\title{
A New Dental Superalloy System: V. Embrittling Phase Transformations
}

\author{
HAMDI MOHAMMED and KAMAL ASGAR
}

School of Dental Medicine, University of Connecticut, Farmington, Connecticut 06032, USA and School of Dentistry, University of Michigan, Ann Arbor, Michigan

The $\sigma$ phase is rich in $\mathrm{Ta}$. When the $\mathrm{Ta}$ concentration is less than $14 \%, \sigma$ does not interfere with the slip mechanism; when the Ta concentration is more than $15 \%$, $\sigma$ interferes with the slip mechanism. The coherent

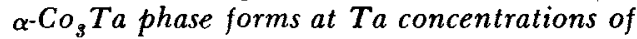
less than $15 \%$, whereas incoherent $\gamma^{-C_{2}} \mathrm{Ta}$ forms only at higher Ta concentrations. The interface between $\sigma$ and the matrix is an important factor in the failure mechanism.

Extensive studies of industrial cobalt (Co) chromium (Cr) alloys showed that the precipitation of topologically close-packed (TCP) phases embrittles the alloys. 1 These phases are referred to by names such as $\sigma, \mu$, $\pi$, and $R$, depending on elements alloyed and their proportions. ${ }^{2}$ The most common of these phases is $\sigma$, which has the general formula $(\mathrm{Co}, \mathrm{Ni})_{x}(\mathrm{Cr}, \mathrm{Mo}, \mathrm{W} \ldots)_{y}$, where $x=1-7$ and $y=1-7$. In Co-base alloys, the $\sigma$ phase is an electron compound with 30 atoms per unit cell arranged in a complex, bodycentered tetragonal structure.

Up to 1957 , the precipitation of $\sigma$ was sought to improve the strength properties of Co-Cr alloys. ${ }^{3}$ The concentrations of $\mathrm{Cr}$ and molybdenum (Mo) were increased to precipitate more $\sigma$. More recently, the deleterious effects of $\sigma$ have been attributed to its consumption of the important strengthening refractory metals and Cr. Sigma also can occur in a platelike fashion, and thus, early fracture is promoted. 4

Currently, the desire to control $\sigma$ phase formation is so strong that an empirical method has been introduced to calculate whether $\sigma$ will form in a given alloy compo-

This paper was presented at the 51 st general session of the IADR in Washington, DC, April 1973.

Received for publication July 6, 1973 . sition. 5 This method is referred to as the phase computation method (PHACOMP) ${ }^{6,7}$

PHACOMP is used to calculate the critical average electron hole number $\left(\bar{N}_{v}\right)$ for a given alloy system. The composition of the alloy system then is adjusted so that the $\bar{N}_{v}$ is less than the critical value; thus, the precipitation of $\sigma$ is prevented. Since this series of articles is about the development of a new alloy system, it may seem appropriate to calculate $\bar{N}_{v}$ for the Co-Cr-nickel (Ni) -tantalum (Ta) system. Despite the ease of calculating $\bar{N}_{r}$ for a given alloy system, the value of such a number is doubtful on three accounts. First, the presence of $\sigma$ has been associated with alloy embrittlement 5,6 ; but it has not been determined whether the precipitation of $\sigma$ itself is the important factor in the failure mechanism or whether the failure is due to other transformations accompanied by $\sigma$ precipitation.

Second, alloys for dental applications with a ductility of $30 \%$ elongation have been reported to be $\sigma$ bearing. ${ }^{8-10}$ The simultaneous presence of $\sigma$ and high ductility indicates that the role of $\sigma$ has been overemphasized.

Third, PHACOMP may be valuable for the development of industrial alloys, but insignificant for the development of biologic alloys. In industry, Co-Cr alloys are used at high temperatures $(\sim 2,200 \mathrm{~F})$. At that temperature the diffusivities of the various elements in a given alloy are so high that phase transformations and precipitation not only happen, but are accelerated. When the composition of a given alloy is such that its average $\bar{N}_{v}$ exceeds the critical value, rapid, massive precipitation of $\sigma$ occurs at the high temperatures and the alloy loses its desirable mechanical properties. In biologic applications, however, the alloy is used at body temperature, where the diffusivity of the ele- 


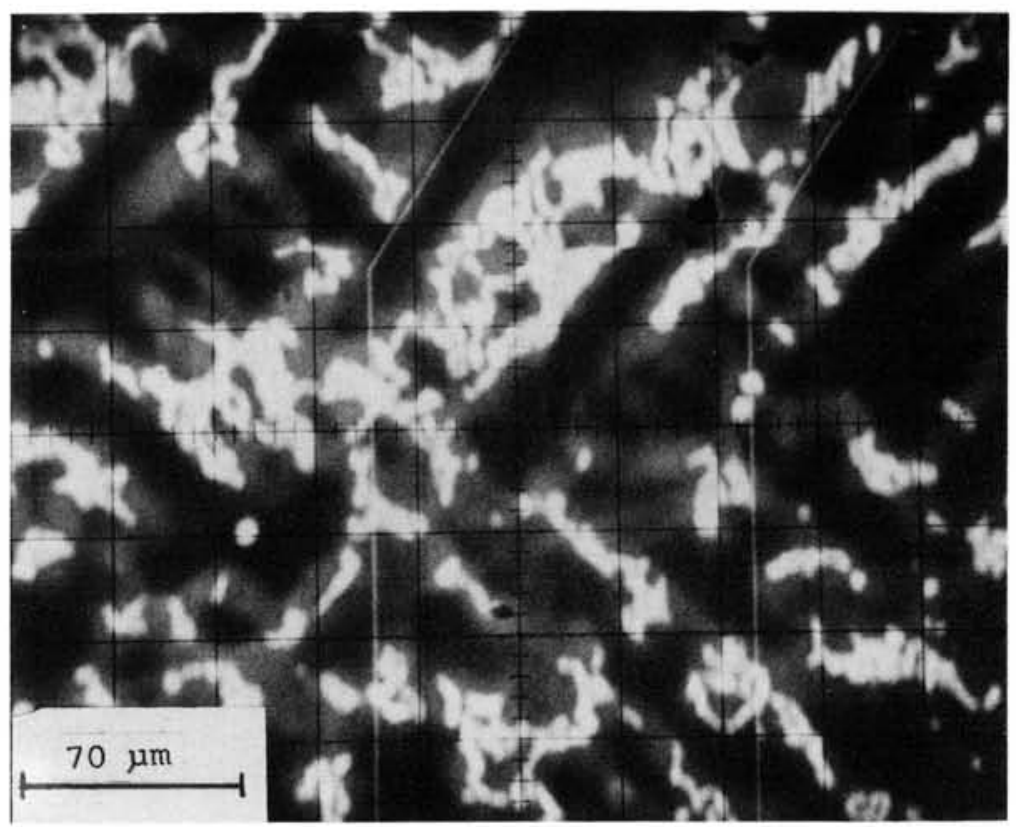

FIG 1.-Electron microprobe sample current image of an alloy containing $14.2 \%$ Ta.

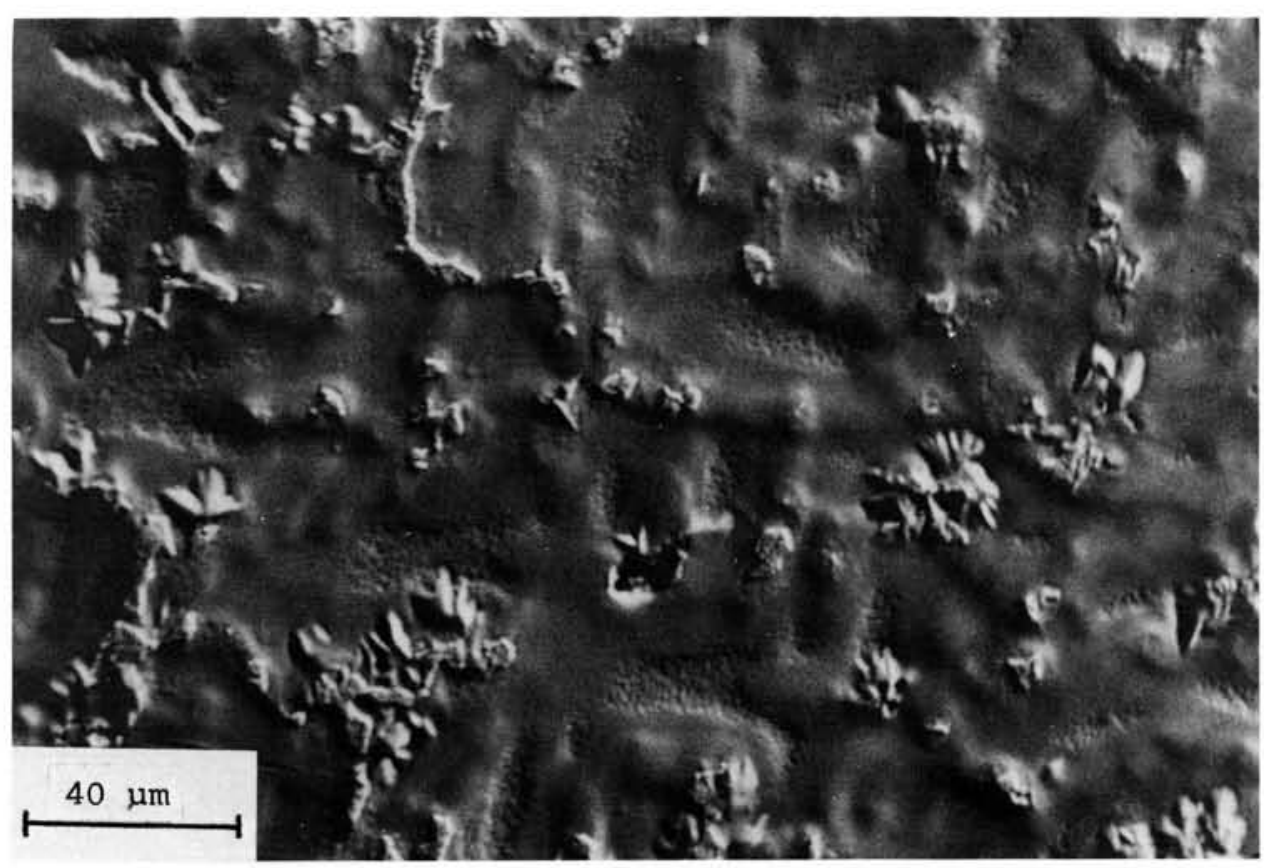

FIG 2.-Microstructure of an alloy containing $16.7 \% \mathrm{Ta}$. 
ments is practically absent. Accordingly, alloys for biologic applications will undergo no transformations during function. If the alloy possesses desirable mechanical properties, its $\sigma$ content may be irrelevant. 10

The purpose of this study was to test the validity of the aforementioned assumptions, to study the role of $\sigma$ in the failure mechanism of the alloys, to determine whether $\sigma$ or other transformations that occur with $\sigma$ precipitation are responsible for failure, and to determine the critical $T$ a concentration for dental applications.

\section{Materials and Methods}

Fifteen alloys of the basic composition 40 $\mathrm{Co}-30 \mathrm{Cr}-30 \mathrm{Ni}$ containing concentrations of $\mathrm{Ta}$ that varied from 0 to $16.7 \%$ were used in this study.

The electron microprobe specimen was similar to the specimen used for metallographic examination, ${ }^{9}$ except that the former was not etched. Sample current and X-ray profile techniques were used to obtain qualitative information about the distribution of the alloying elements within the observed phases.

The sample current technique depends on the fact that the absorption of electrons generally decreases with an increase in the average atomic number of a given area within the sample. In a system such as $\mathrm{Co}-\mathrm{Cr}-\mathrm{Ni}-\mathrm{Ta}$, variations in the distribution of $\mathrm{Ta}$ produce readily detectable variation in sample current because of the large difference between the atomic number of $\mathrm{Ta}$ (73) and that of the base elements $\mathrm{Co}, \mathrm{Cr}$, and $\mathrm{Ni}(27,28,24$; average, 26). Regions that are richer in $\mathrm{Ta}$ have a higher average atomic number and appear lighter in sample current images than regions with a lower average atomic number.

In using the X-ray profile technique, an electron beam was passed across the surface in a straight line, while a spectrometer recorded the intensity of a particular characteristic X-ray line. The output of the spectrometer was recorded as an oscilloscope trace. If, for example, the X-ray line is characteristic of $\mathrm{Ta}$, a Ta-rich region in the path of the beam will result in a positive peak in the oscilloscope trace.

The role of $\sigma$ in the failure mechanism was studied by use of the microbend test.11

FIG 3.-X-ray profiles of alloy containing $7.4 \%$ Ta.

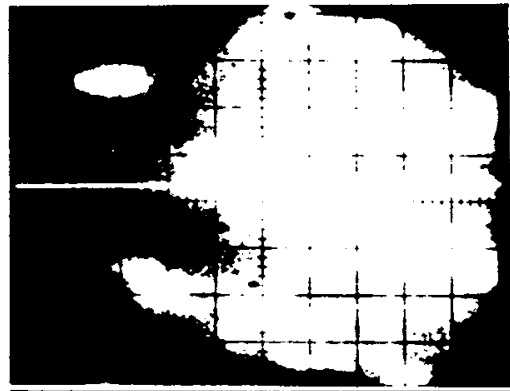

$\mathrm{Ta}$

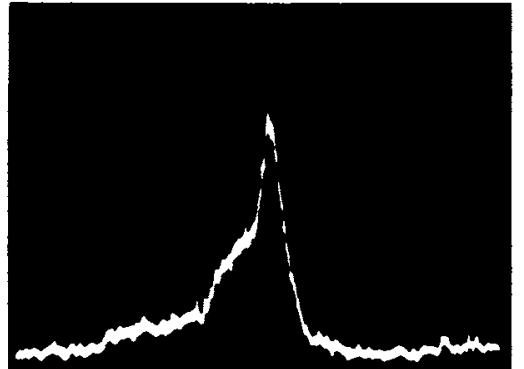

Co

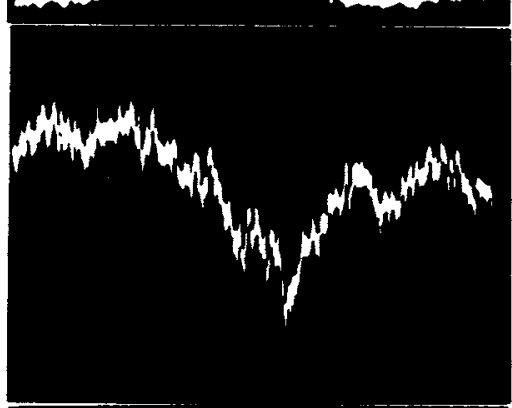

$\mathrm{Ni}$

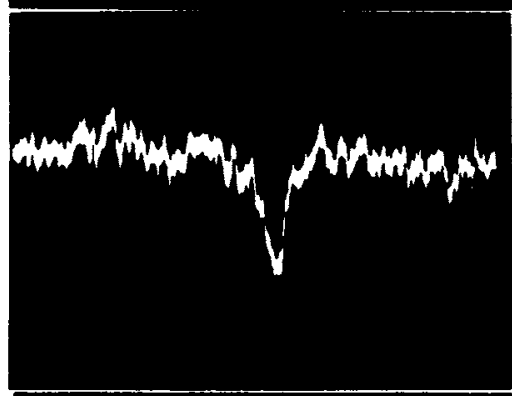

Cr

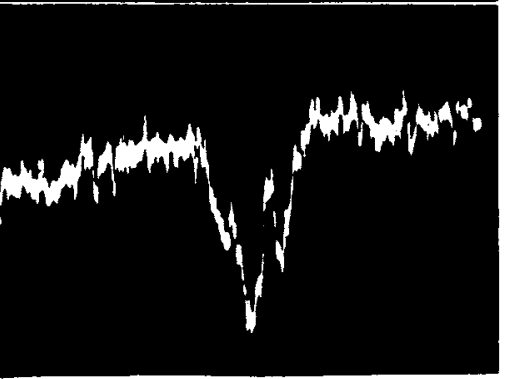

$100 \mu \mathrm{m}$. 

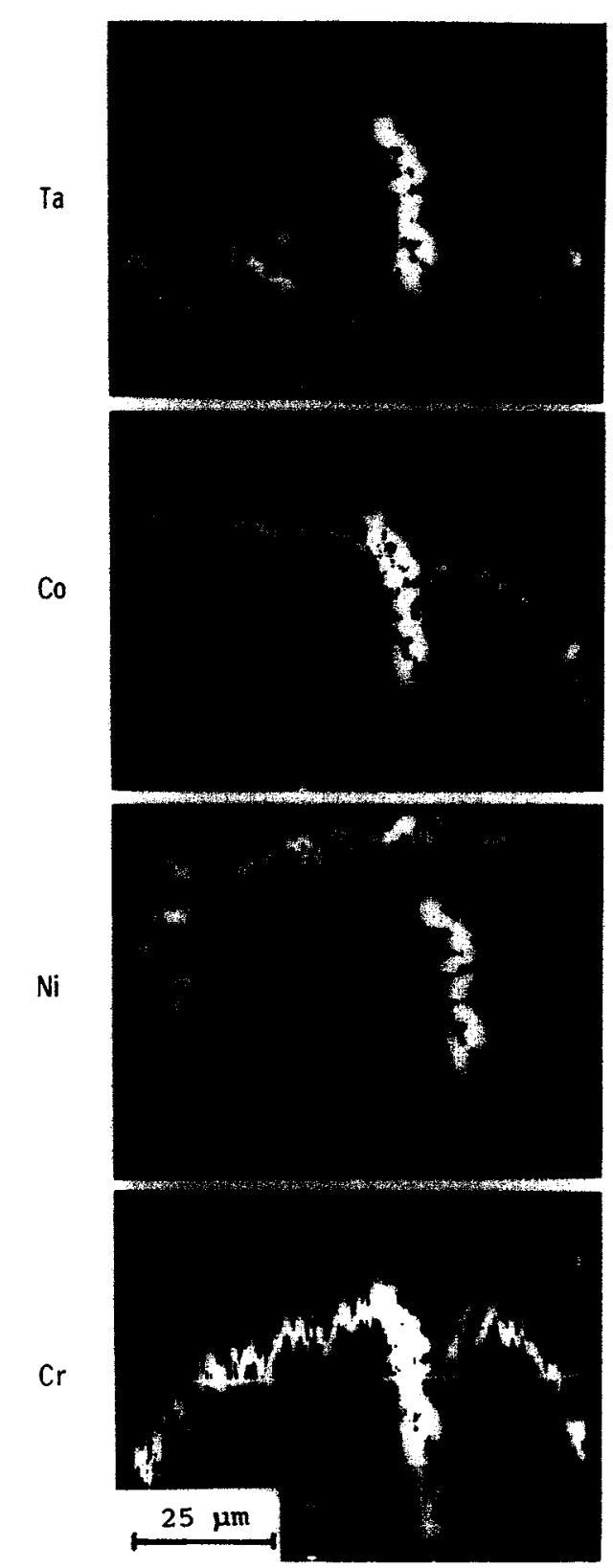

FIG 4.-X-ray profiles of alloy containing $10.7 \%$ Ta.

This method of testing requires the preparation of a specimen of about an inch long with a square cross section of a sixteenth of an inch. Combustible plastic was cut to this size and was used as a pattern for the specimen. The specimens were mounted in a plastic base, polished, etched, removed from their mounts, and placed in Flinn's strain viewer, a which permits the application of gradual stress to the specimen while the microstructure is under observation.

\section{Results}

A previous study 9 concerning the microstructure of the alloy system showed that quantities of the $\sigma$ phase increased gradually with the $\mathrm{Ta}$ concentration and increased rapidly at a concentration of $13 \% \mathrm{Ta}$.

$\mathrm{X}$-ray diffraction analysis ${ }^{10}$ showed that the number of lines characteristic of $\sigma$ and their intensities increased as the Ta concentration increased, that $\alpha-\mathrm{Co}_{3} \mathrm{Ta}$ formed in alloys containing more than $5 \% \mathrm{Ta}$, and that $\gamma$ - $\mathrm{Co}_{2} \mathrm{Ta}$ formed only in alloys containing more than $15 \%$ Ta.

Electron microprobe analysis with the sample current technique indicated three regions of distinct $\mathrm{Ta}$ concentrations: a $\mathrm{Ta}$ rich region (white), a region of intermediate $\mathrm{Ta}$ content (gray), and a Ta-poor region (black). The sample current image of an alloy containing $14.2 \% \mathrm{Ta}$ is shown in Fig. ure 1. Scanning electron microscopic examination of the alloys showed that the Ta-rich phases precipitated interdendritically, as shown in Figure 2.

X-ray profiles of alloys containing 7.4 and $10.7 \%$ Ta are depicted in Figures 3 and 4 . It is evident that the interdendritic phase is richer in $\mathrm{Ta}$ and depleted from $\mathrm{Co}, \mathrm{Cr}$, and $\mathrm{Ni}$ relative to the matrix phase.

A typical result from microbend testing of alloys containing up to $12.7 \% \mathrm{Ta}$ is depicted in Figure 5. As the bending of the test beam was increased gradually, slip occurred and increased in magnitude, as indicated by the traces of the slip lines observed. The traces of the slip lines are continuous from the matrix to the interdendritic phase and back to the matrix. Beams of alloys containing up to $12.7 \%$ Ta were bent to the maximum limits of the strain viewer to form an angle of $120^{\circ}$ without fracture.

When alloys containing more than $13 \%$ Ta were tested, the application of gradual strain caused $\sigma$ regions to interconnect and form a continuous fracture line, as shown in Figure 6 of an alloy containing 14.2\% Ta. The $\sigma$ regions closest to the fracture line also were interconnected (Fig 7). The traces of the slip lines in alloys containing more than

\footnotetext{
Model 4350, Dietert Co., Detroit, Mich.
} 


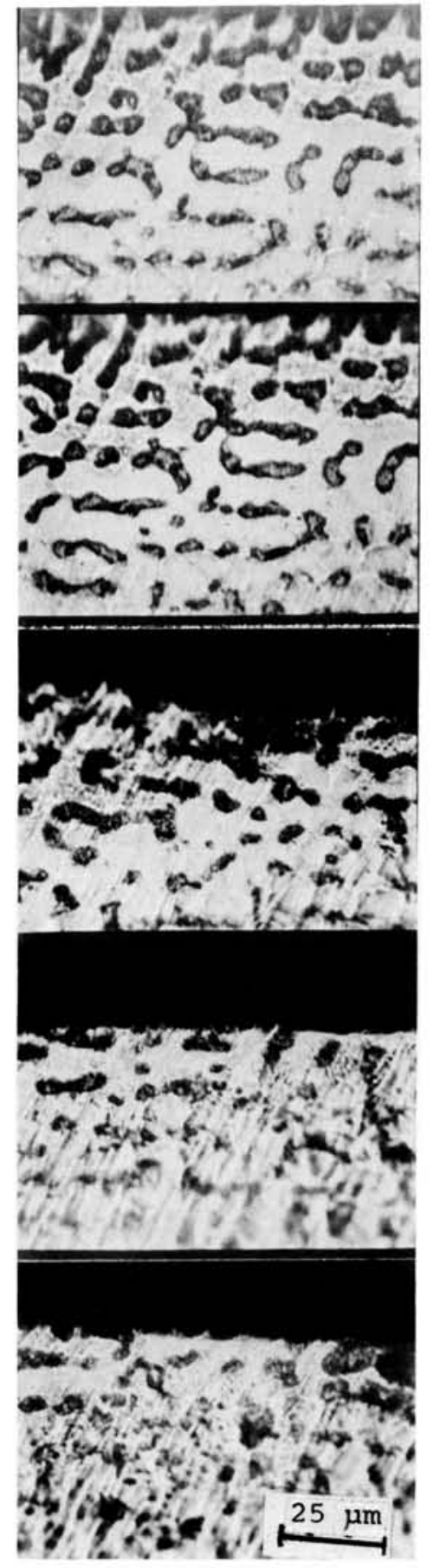

Fic 5.-Microstructure of alloy containing $12.7 \% \mathrm{Ta}$ and subjected to increasing increments of strain.
$13 \% \mathrm{Ta}$ were not continuous; rather, the traces were interrupted by the interdendritic $\sigma$ regions, as shown in Figure 7.

\section{Discussion}

The increase in the concentrations of $\sigma$ with the increase in $\mathrm{Ta}^{9}$ may be explained with PHACOMP. The $\bar{N}_{v}$ of Ta is 5.66 , whereas that of $\mathrm{Ni}$ is 0.66 . This means that the presence of 1 atomic $\%$ of $\mathrm{Ta}$ in solid solution in the alloy will raise the $\bar{N}_{v}$ of its matrix to an extent similar to the addition of $8.57(5.66 \div 0.66)$ atomic \% of $\mathrm{Ni}$.

These facts explain the effect of $\mathrm{Ta}$ in raising the $\bar{N}_{v}$, and hence the precipitation of $\sigma$. They do not explain the sudden increase in $\sigma$ formation in alloys containing more than $13 \%$ Ta. The latter may be explained as follows: The calculation of $N_{v}$ takes into consideration the amount of elements present in solid solution only, and discounts those consumed in the formation of various precipitates. Results of X-ray diffraction 10 indicated that an addition of up to $5 \% \mathrm{Ta}$ to the alloy was consumed as solid solution. Such a concentration of $\mathrm{Ta}$ did not cause enough precipitation to be detectable by X-ray diffraction. Increasing $\mathrm{Ta}$ to more than $5 \%$ caused the precipitation of $\alpha \cdot \mathrm{Co}_{3} \mathrm{Ta}$. In other words, up to $5 \% \mathrm{Ta}$ should be considered in calculating the $\bar{N}_{v}$; amounts of $\mathrm{Ta}$ beyond that concentration are consumed in the formation of the $\alpha$. $\mathrm{Co}_{3} \mathrm{Ta}$ phase. Accordingly, these additional concentrations of $\mathrm{Ta}$ should be discounted when the $\bar{N}_{v}$ is calculated and should not contribute to the formation of $\sigma$. Additions of more than $13 \%$ Ta were neither tolerated in the matrix as a solute nor reacted with the alloy elements to precipitate. Tantalum concentrations of more than $13 \%$ were consumed, primarily in the formation of $\sigma$. These factors may explain the sudden increase in $\sigma$ concentration with $\mathrm{Ta}$ concentrations of more than $13 \%$.

The fact that $\sigma$ precipitates interdendritically (Fig 2) and is rich in Ta but not in Co-Cr-Ni (Figs 3, 4) supports the aforementioned explanation. The interdendritic precipitation of $\sigma$ means that the dissolution rate of $\mathrm{Ta}$ in the alloys decreased with temperature. As cooling progressed, dendritic formation began. Concentrations of $\mathrm{Ta}$ exceeding the solubility limit were segregated toward the periphery of the dendrite. At 


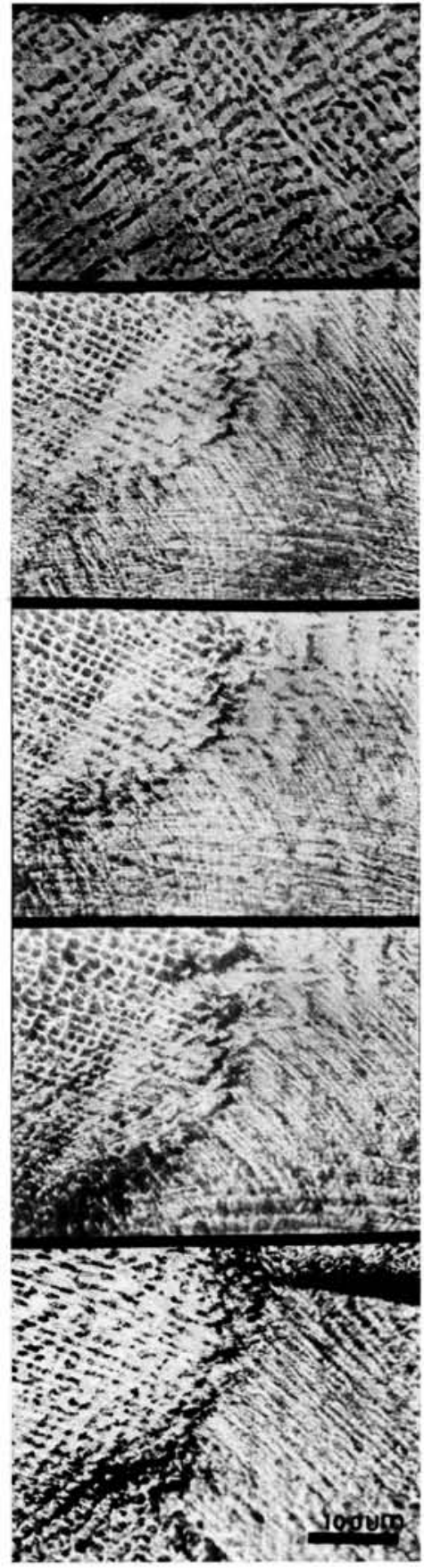

FIG 6.-Microstructure of alloy containing $14.2 \% \mathrm{Ta}$ and subjected to increasing increments of strain.

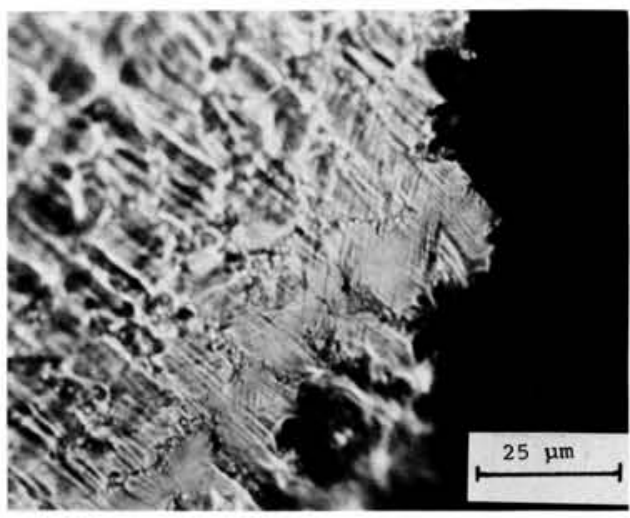

Fic 7.-Microstructure of an alloy containing $16.7 \% \mathrm{Ta}$ after fracture. Notice interconnection of $\sigma$.

one stage of cooling, the concentration of Ta at the periphery of the dendrite reached the atomic ratio of $3 \mathrm{Co:} 1 \mathrm{Ta}$, which was ideal for the precipitation of $\alpha-\mathrm{Co}_{3} \mathrm{Ta}$. At a later stage of cooling (and further toward the periphery of the dendrite), the atomic ratio was $2 \mathrm{Co}: \mathrm{l} \mathrm{Ta}$, which was ideal for the precipitation of $\gamma \cdot \mathrm{Co}_{2} \mathrm{Ta}$. At a later time, the concentration of $\mathrm{Ta}$ was so high that it required the precipitation of a new phase capable of consuming such high $\mathrm{Ta}$ concentrations. In the latter instance, Ta may be consumed by the precipitation of $\sigma$, which can be assigned the composition of up to $\mathrm{CoTa}_{7}$. This explanation is supported by Figure 1. In this figure, the core of the dendrite (black) has the lowest average atomic number, or is poorest in $\mathrm{Ta}$. This layer is a solid solution of $\mathrm{Ta}$ in $\mathrm{Co}-\mathrm{Cr}-\mathrm{Ni}$, and possibly $\alpha-\mathrm{Co}_{3} \mathrm{Ta}$. Peripheral to that layer (gray), a layer of medium average atomic weight, and hence of average $\mathrm{Ta}$ contents, is evident. This layer is primarily $\alpha-\mathrm{Co}_{3} \mathrm{Ta}$ and $\gamma-\mathrm{Co}_{2} \mathrm{Ta}$. The interdendritic phase (white) has the highest average atomic weight and hence the highest Ta content.

Probe ratios of the various elements in the white, gray, and black regions were determined. X-ray counts were obtained from the pure elements and then from the three regions in the alloy. The ratio of the counts obtained for a given element in a particular region of the alloy to the counts obtained for that element in its pure condition is called the probe ratio. Since quantitation was not sought in this study, correction factors were not considered in determining the probe ra- 
TABLE 1

Probe Ratios for an Alloy Containing $7.4 \%$ TA

\begin{tabular}{cccc}
\hline & \multicolumn{3}{c}{ Region } \\
\cline { 2 - 4 } Element & White & Gray & Black \\
\hline $\mathrm{Co}$ & 40.2 & 47.9 & 53.4 \\
$\mathrm{Ni}$ & 25.6 & 30.4 & 32.0 \\
$\mathrm{Cr}$ & 24.7 & 24.7 & 27.6 \\
$\mathrm{Ta}$ & 9.3 & 5.3 & 1.8 \\
\hline
\end{tabular}

tios. Tables 1 to 3 show the probe ratios for the alloys containing 7.4, 10.7, and $14.2 \%$ Ta. All tables show that the interdendritic or white region is richest in $\mathrm{Ta}$ and poorest in $\mathrm{Co}, \mathrm{Ni}$, and $\mathrm{Cr}$ in all alloys. The tables also show that the periphery of the dendrite or the gray region is richer in $\mathrm{Ta}$ and generally poorer in $\mathrm{Co}, \mathrm{Cr}$, and $\mathrm{Ni}$ when compared with the core of the dendrite (the black region).

Our data showed that the addition of $\mathrm{Ta}$ caused the precipitaton of $\sigma$. The data did not show the effect of $\sigma$ on the mechanical properties.

The results of microbend testing, Figures 5 and 6 , showed that at concentrations of up to $13 \% \mathrm{Ta}$, the $\sigma$ phase was present and increased as the $\mathrm{Ta}$ concentration increased, but it played no role in the mechanism of failure. At greater concentrations of Ta, the $\sigma$ regions were interconnected, formed a continuous fracture line, and caused ultimate failure. Although $\sigma$ was present in all alloys, it formed microcracks only when the concentration of $\mathrm{Ta}$ was more than $13 \%$. Such differences may be explained as a result of the fact that the interphase interface between $\sigma$ and the matrix is coherent ${ }^{7}$ when $\mathrm{Ta}$ concentrations are less than $13 \%$ and incoherent when higher Ta concentrations are present. This explanation is supported by the results of the microbend test and X-ray diffraction.10

The microbend test (Fig 5) shows that

TABLE 2

Probe Ratios for an alloy Containing $10.7 \%$ TA

\begin{tabular}{cccc}
\hline & \multicolumn{3}{c}{ Region } \\
\cline { 2 - 4 } Element & White & Gray & Black \\
\hline Co & 30.8 & 33.8 & 34.7 \\
$\mathrm{Ni}$ & 21.8 & 32.7 & 27.0 \\
$\mathrm{Cr}$ & 13.7 & 17.2 & 18.6 \\
$\mathrm{Ta}$ & 9.6 & 6.8 & 2.5 \\
\hline
\end{tabular}

TABLE 3

Probe Ratios for an alloy Containing $14.2 \%$ TA

\begin{tabular}{crrr}
\hline & \multicolumn{3}{c}{ Region } \\
\cline { 2 - 4 } Element & White & Gray & Black \\
\hline Co & 39.4 & 41.8 & 41.4 \\
$\mathrm{Ni}$ & 13.3 & 14.6 & 17.6 \\
$\mathrm{Cr}$ & 4.2 & 6.6 & 8.4 \\
$\mathrm{Ta}$ & 22.8 & 11.9 & 5.7 \\
\hline
\end{tabular}

the traces of the slip lines are continuous through $\sigma$ regions; therefore, the interface is coherent in nature and the change in the lattice constant varies gradually from the matrix to the interface to the interdendritic precipitate. The coherent interface in this instance is $\alpha-\mathrm{Co}_{3} \mathrm{Ta}$, since it is the only coherent phase possible.

X-ray diffraction supported our results. The Co-Ta precipitate formed with increasing $\mathrm{Ta}$ concentration (up to $14 \% \mathrm{Ta}$ ) was the coherent $\alpha-\mathrm{Co}_{3} \mathrm{Ta}$ phase. Beyond the $14 \%$ concentration, the incoherent phase, $\gamma$ $\mathrm{Co}_{2} \mathrm{Ta}$, was evident. Since solidification required the cored arrangement matrix, $\alpha-\mathrm{Co}_{3}$. $\mathrm{Ta}-\gamma-\mathrm{Co}_{2} \mathrm{Ta}-\sigma$, it is reasonable to conclude that the matrix- $\sigma$ interface at $\mathrm{Ta}$ concentrations greater than $14 \%$ is made from the incoherent $\gamma-\mathrm{Co}_{2} \mathrm{Ta}$ phase. There is no gradual change in the lattice parameter from the matrix and $\alpha-\mathrm{Co}_{3} \mathrm{Ta}$ to $\gamma-\mathrm{Co}_{2} \mathrm{Ta}$ or $\sigma$. In the latter instance, $\sigma$ may be considered a foreign phase "uncoupled" to the matrix. Being surrounded with the incoherent $\gamma$ $\mathrm{Co}_{2} \mathrm{Ta}$ phase, $\sigma$ forms microcracks that propagate and interconnect under load.

\section{Conclusions}

The experimental evidence of this study leads to the following conclusions: PHACOMP is applicable to the Co-Cr-Ni-Ta system, with the exception that the critical $\bar{N}_{v}$ for the system is not one at which $\sigma$ forms, but one at which the $\sigma$-matrix interface becomes incoherent. The interface between $\sigma$ and the matrix is a more important factor in the failure mechanism of the alloys than the precipitation of $\sigma$ per se. Tantalum may cause excessive precipitation of $\sigma$ if it is used in concentrations that exceed its solubility limit in the alloy and that are in excess of those needed for the precipitation of $\alpha-\mathrm{Co}_{3}$ $\mathrm{Ta}$. The critical $\mathrm{Ta}$ concentration for the $40 \mathrm{Co}-30 \mathrm{Ni}-30 \mathrm{Cr}$ alloy base is 13 to $14 \%$. 
The advice of R. G. Craig to the senior author during his residence at the University of Michigan is gratefully acknowledged.

\section{References}

l. Beattie, H.J., Jr., and Hagel, W.C.: Compositional Control of Phases Precipitating in Complex Austenitic Alloys, Trans AIME 233: 277, 1965.

2. Hall, E., and Algie, S.: The Sigma Phase, J Inst Metals 11: 61, 1966.

3. Silverman, R.; Arbiter, $W$; and Hodi, F.: Effect of Sigma Phase on Co-Cr-Mo Base Alloys, Trans ASM 49: 805, 1957.

4. Sims, C.T.: A Contemporary View of Cobalt Base Alloys, J Metals 21: 27-42, 1969.

5. Boesch, W.J., and Slaney, J.S.: Preventing Sigma Phase Embrittlement in Nickel-Base Superalloys, Metal Progress 86: 109, 1964.

6. MURPHY, H.J.; SIMS, C.T.; and BELTraN,
A.M.: PHACOMP Revisited, J Metals 20: $46,1968$.

7. Mohammed, H., and Asgar, K.: A New Dental Superalloy System: I. Theory and Alloy Design, J Dent Res 52: 196, 1973.

8. Mohammed, H., and Asgar, K.: A New Dental Superalloy System: II. Mechanical Properties, $J$ Dent Res 52: 145, 1973.

9. Монамmed, H.; Asgar, K.; and Bigelow, W.C.: A New Dental Superalloy System: III. Microstructure and Phase Transformations, J Dent Res 52: 151, 1973.

10. Mohammed, H.; Asgar, K.; and Kimball, O.F.: A New Dental Superalloy System: IV. X-Ray Diffraction Analysis, $J$ Dent Res 52: 744-749, 1973.

11. Flinn, R.A., and Trojan, P.K.: Examination of Microstructures Under Varying Stress, Metal Progress 68: 88, 1955. 